\title{
Determination of the relationship between the fatigue and social support levels of cancer patients: a cross-sectional study
}

\author{
Meltem Akbas ${ }^{1}$, Sule Gokyildiz Surucu ${ }^{1}$, Emine Akca ${ }^{2}$, and Cemile Onat Koroglu ${ }^{1}$
}

${ }^{1}$ Department of Midwifery, Cukurova University Faculty of Health Sciences, Adana; ${ }^{2}$ Department of Midwifery, Inonu University Faculty of Health Sciences, Malatya, Turkey

Received: January 8, 2019

Revised : August 21, 2019

Accepted: October 2, 2019

\section{Correspondence to}

Meltem Akbas, Ph.D.

Department of Midwifery, Cukurova University Faculty of Health Sciences, o1330 Saricam, Adana, Turkey

Tel: +90-322-338-64-84

Fax: +90-322-338-69-70

E-mail: makbaskanat@gmail.com https://orcid.org/0000-0002-

5845-0552
Background/Aims: Cancer is seen as one of the most important health problems of our time. In the world and in our country, the most common death cause after cardiovascular diseases in the order of diseases that result in death is cancer. This descriptive, cross-sectional study is done in order to determine the relationship between fatigue and social support levels of cancer patients.

Methods: Research was carried out in Cukurova University Hospital in Adana, which is located in the south of Turkey, between December 2014 and December 2015. Data were collected by interview form prepared by the researcher, Piper Fatigue Scale and Social Support Patient Form. Data was analyzed by percentile, mean, independent $t$ test, one-way analysis of variance, correlation and multiple regression.

Results: The average score of Social Support Patient Form is $131.1 \pm 15.5$, and Piper Fatigue Scale total score mean of the participants is $5.8 \pm 2.4$. A low level of negative correlation was found between the social support to cancer patients scale emotional support subdimension and the Piper Fatigue Scale affective subdimension.

Conclusions: As a result of the research, it was seen that the level of fatigue of the participants had moderate and level of perceived social support was positive. The age, marital status, and education status of the participants do not affect the fatigue and social support levels.

Keywords: Neoplasms; Fatigue; Social support

\section{INTRODUCTION}

Cancer, defined as the uncontrolled and abnormal cell proliferation, is used as a general term for many diseases and it is seen as one of the most important health problems of our time. In the world and in our country, the most common death cause after cardiovascular diseases in the order of diseases that result in death is cancer [1-3].

Although new treatment modalities have increased the hope level of cancer patients, the long treatment pe- riod, the difficulties of treatment and its effects lead to many side effects in the patient. The most common of these side effects is fatigue. Fatigue is a symptom that develops over time, has psychological, cognitive and emotional elements and it manifests itself with diminished energy and increased need for rest, concentration, motivation and restriction of daily activities [3]. Patients describes fatigue by using the words such as; tiredness, weakness, exhaustion, somnolence, getting tired quickly, slowing, lack of energy or absence of energy, insom- 
nia and lassitude [4].

Cancer-related fatigue causes disruption in all aspects of quality of life and may be a risk factor for reduced survival [5]. Fatigue has many destructive effects on cancer patients from physical, psychological and socioeconomic aspects. Cancer patients define fatigue as a devastating symptom during the months and years of treatment. Fatigue is also described by patients as "reduction in performance power, lack of energy, drowsiness, depression, difficulty in concentrating, lack of motivation and insomnia" [6].

Along with fatigue, normal activity capacity of patients is diminished, and patients cannot perform the activities which they have always performed for a long time. This situation affects the life quality of patients negatively. According to Karakoc [3], this symptom, which interferes with individual functions and lowers the quality of life, is an important problem that is skipped over in clinics because it is a subjective phenomenon and it is a universally accepted aspect of diseases. For this reason, the evaluation of the symptom and the establishment of necessary initiatives to cope with it may increase the quality of life of the individual [3].

Nurses have an important task in the training of cancer patients and in increasing their coping skills. The nurse is responsible for monitoring the objective and subjective findings of the fatigue symptom by constantly evaluating the factors affecting fatigue, which has an important effect on the quality of life of cancer patients, and for making plans for appropriate interventions for both the patient and the family $[3,7]$.

Individuals with cancer need social support so that they are least affected by many of the symptoms they experience and that they can cope with the disease. Social support is defined as all interpersonal relationships that have an important place in people's lives and that can provide emotional, material and cognitive assistance when needed and as social support systems that have health protection function. Social support helps to reduce the harmful effects of physical illness and self-esteem linked to negative events in life and to function as a buffer against these negative events $[8,9]$. This support is very important for the patient receiving cancer treatment to beat the disease and to feel psychologically comfortable.

\section{Research questions}

(1) What is the level of social support that individuals with cancer receive from their family?

(2) What is the level of fatigue of the individual with cancer?

(3) Is there a relation between the social support that the individuals with cancer receive from their families and the level of fatigue?

(4) What are the factors affecting the level of social support that individuals with cancer receive from their parents and the level of fatigue?

\section{Aim}

This research aims to determine the relationship between fatigue levels of cancer patients and the social support they receive.

\section{METHODS}

\section{Type of the research}

The research is descriptive and cross-sectional.

\section{The population and sample of the research}

The research was carried out at Cukurova University Faculty of Medicine Balcali Hospital. The patients in the gynecologic-oncology service of the relevant hospital between December 1, 2014 and December 1, 2015 constituted the population of the research. The gynecological cancer patients who undergo only chemotherapy treatment are admitted to this clinic. Because the patients received chemotherapy more than once, data were collected once from the hospitalized patients. The criteria for sampling included voluntary participation of the cancer patient, not being in the terminal stage of the illness and not having had a surgical operation. Cancer patients who agreed to participate in the study, were not in terminal phase, they had not undergone a surgery at the time. Fifty patients who met the research criteria during the time of the research were included in the study. Twenty-seven patients were hospitalized more than once in the clinic. Eight patients that were in terminal phase, 25 patients who had undergone a surgery and three patients who did not want to participate in the study were not sampled. 


\section{Data collection}

In data collection phase, in order to identify the characteristics of participants, 'Patient Identification Form' which was prepared by the researchers was used to evaluate the level of fatigue of the patients 'Piper Fatigue Scale' (PFS) and to determine the social support perception of the cancer patients 'Social Support Patient Form' were used $[6,10]$. Forms were distributed to literate patients and were collected after 30 minutes. For illiterate patients, face to face interviews were conducted to collect data.

\section{Patient identification form}

It was developed by researchers and consists of 18 items that include sociodemographic features of the cancer patient (age, marital status, education level, work status, social security, and number of children), diagnosis, time of diagnosis, treatments/therapies, people living in same house, care at home, relationship with partner-child-relatives-friends and frequency of hospital visit.

\section{Piper Fatigue Scale}

PFS, was developed in 1987 by Piper et al. with the aim of evaluating the multifaceted measurement model of fatigue $[11,12]$. The PFS is composed of 22 items, and the participants evaluate the visual comparison scale, which varies between o to 10 points. In the scale, participants' subjective perception of fatigue is evaluated based on four subdimensions; behaviour/violence subdimension, affective subdimension, sensory subdimension, and cognitive/psychological subdimension. The total fatigue score is calculated by dividing the total score of 22 items by the number of items. According to the result obtained; o points indicates no fatigue at all, 1 to 3 points indicates mild fatigue, 4 to 6 points indicates moderate fatigue, 7 to 10 points indicates severe fatigue. Validity and reliability study of this scale in our country was made by Can [11]. Scale is a measure that can be used in cancer patients and their relatives. In the study, the Cronbach's alpha $(\alpha)$ reliability coefficient was found to be between 0.87 to 0.91 for the subgroups and 0.94 for the scale $[11,12]$.

\section{Social Support Patient Form}

Developed by Eylen [6], the scale was developed to determine the type and level of social support that patients consider to receive form their family members. The scale consisting of 35 elements is 5 point likert type and has three subdimensions. Trust support, emotional support, and information support are subdimensions of the scale. Thirteen of the items $(4,9,13,14,21,22,26,27,29,30,31$, $32,33)$ under measurement tool are negative and 22 are positive statements. In positive items, the answers given are given codes such as "it matches very well with my situation (5 point), it matches with my situation (4 point), it partially matches with my situation (3 point), it does not match with my situation ( 2 point), and it does not match at all with my situation (1 point) and for negative items same options are coded by scoring them from 1 to 5 . The perceived social support score equals the sum of the scores from the positive items plus the scores from the reversal of the scores of the negative items. The lowest score that can be obtained from the scale is 35 and the highest score is 175 . The high score on the scale indicates that the social support that the cancer patient receives from his/her family is high. The first factor, trust support subdimension, composes of 13 items $(1,3,6,7,8,10,11$, $12,17,19,24,34,35)$, the second factor, emotional support subdimension, composes of 12 items $(2,9,13,15,16,18,20$, $23,26,27,28,33)$ and the third factor, information support subdimension, composes of 10 items $(4,5,14,21,22,25,29$, 30, 31, 32). The alpha coefficients of each subdimension were 88 ( $\mathrm{n}=89$, number of items 13) for the "trust support" subdimension, 0.88 ( $\mathrm{n}=89$, number of items 12) for the "emotional support" subdimension and 0.87 ( $\mathrm{n}=89$, number of items 10) for the "information support" subdimension. These findings have been interpreted in a way that the items can distinguish between those who receive social support and those who do not [6].

\section{Statistical analysis}

Data were analyzed using IBM SPSS Statistics 20 (IBM Co., Armonk, NY, USA) program using descriptive and parametric statistical analysis methods. Descriptive statistical analyses involved calculation of means, standard deviations, frequencies, and minimum and maximum values. Comparisons were performed using a $t$ test for the comparisons of two groups and one-way analysis of variance for the comparison of three and more groups. Pearson Correlation Analysis was used to evaluate the relationship between the scale scores. Multiple regression model was used to determine the effect of indepen- 
Table 1. Findings on the diagnosis and treatment process of a cancer patient $(n=50)$

\begin{tabular}{|c|c|}
\hline Variable & No. (\%) \\
\hline \multicolumn{2}{|l|}{ Diagnosis (self report of patients) } \\
\hline Ovary cancer & $30(60.0)$ \\
\hline Endometrium cancer & $7(14.0)$ \\
\hline Does not know & $10(20.0)$ \\
\hline Cervix cancer & $3(6.0)$ \\
\hline \multicolumn{2}{|l|}{ Diagnosis time } \\
\hline 1 year ago & $25(50.0)$ \\
\hline 2 years ago & $23(46.0)$ \\
\hline Does not know & $2(4.0)$ \\
\hline \multicolumn{2}{|l|}{ Previous treatment } \\
\hline Chemotherapy & $45(90.0)$ \\
\hline Surgical treatment & $17(34 \cdot 0)$ \\
\hline Medicinal treatment & $6(12.0)$ \\
\hline Radiotherapy & $1(2.0)$ \\
\hline \multicolumn{2}{|l|}{ Persons with whom the patients share home } \\
\hline Him/herself, spouse and children & $27(54.0)$ \\
\hline Him/herself and spouse & $8(16.0)$ \\
\hline Him/herself and children & $8(16.0)$ \\
\hline $\begin{array}{l}\text { Him/herself, his/her mother, father } \\
\text { and sibling }\end{array}$ & $2(4.0)$ \\
\hline Him/herself, daughter and grandchild & $1(2.0)$ \\
\hline His/her mother and children & $1(2.0)$ \\
\hline \multicolumn{2}{|l|}{ Persons who provide home care to the patient } \\
\hline First degree relative & $41(82.0)$ \\
\hline Second degree relative & $9(18.0)$ \\
\hline \multicolumn{2}{|l|}{ Level of relations with persons } \\
\hline \multicolumn{2}{|l|}{ Partner } \\
\hline Good & $28(56.0)$ \\
\hline Moderate & $9(18.0)$ \\
\hline Do not have partner & $13(26.0)$ \\
\hline \multicolumn{2}{|l|}{ Children } \\
\hline Good & $45(90.0)$ \\
\hline Moderate & $2(4.0)$ \\
\hline Do not have child & $3(6.0)$ \\
\hline \multicolumn{2}{|l|}{ Friends } \\
\hline Good & $43(86.0)$ \\
\hline Moderate & $7(14.0)$ \\
\hline \multicolumn{2}{|l|}{ Relatives } \\
\hline Good & $44(88.0)$ \\
\hline Moderate & $6(12.0)$ \\
\hline
\end{tabular}

Table 2. Findings related to the social support perception scale and Piper Fatigue Scale average scores of cancer patients $(n=50)$

\begin{tabular}{|c|c|c|}
\hline Scale & Mean \pm SD & $\begin{array}{c}\text { Range } \\
\text { of distribution }\end{array}$ \\
\hline \multicolumn{3}{|c|}{ Social support perception scale of cancer patients } \\
\hline Trust support & $58.8 \pm 6.8$ & $38-65$ \\
\hline Emotional support & $41.9 \pm 5.7$ & $30-60$ \\
\hline İnformation support & $30.4 \pm 7.2$ & $18-48$ \\
\hline Total & $131.1 \pm 15.5$ & $91-171$ \\
\hline \multicolumn{3}{|l|}{ Piper Fatigue Scale } \\
\hline Behavioral/severity & $5.9 \pm 3.1$ & $0-10$ \\
\hline Affective meaning & $6.4 \pm 3.0$ & $0-10$ \\
\hline Sensory & $6.4 \pm 2.6$ & $0-10$ \\
\hline Cognitive/mood & $4.8 \pm 2.3$ & $0-9$ \\
\hline Total & $5.8 \pm 2.4$ & $5-38$ \\
\hline
\end{tabular}

dent variables on dependent variable. Statistical significance level was 0.05 .

\section{Ethical statement}

Approval from a University Faculty of Medicine Non-Invasive Clinical Research Ethics Committee was obtained on May 07, 2013 (approval number: 17/8), and permission from the hospitals and informed consent from the patients participating in the study were obtained.

\section{RESULTS}

All patients were women. The average age of the participants was $56.0 \pm 11.0$ and the range of distribution was 23 to 81 . The $74.0 \%$ of the participants were married, $92.0 \%$ did not work, $82.0 \%$ expressed the economic status as moderate, and $62.0 \%$ had primary education and above.

In Table 1, findings on the diagnosis and treatment process of a cancer patient are shown. It was found out that $60.0 \%$ of cancer patients had ovary cancer, $50.0 \%$ of them were diagnosed a year ago and $90.0 \%$ of them received chemotherapy as a treatment method. It was observed that $54.0 \%$ of the cancer patients who participated in the study had lived with their spouses and their children, $82.0 \%$ of the people who provided care to them were their first-degree relative, and that most of them 
Table 3. Findings related to the relationship between social support perceptions and fatigue levels of cancer patients $(\mathrm{n}=50)$

\begin{tabular}{|c|c|c|c|c|c|}
\hline \multirow[b]{2}{*}{ Variable } & \multicolumn{5}{|c|}{ Piper Fatigue Scale } \\
\hline & $\begin{array}{c}\text { Behavioral/ } \\
\text { severity }\end{array}$ & $\begin{array}{l}\text { Affective } \\
\text { meaning }\end{array}$ & Sensory & $\begin{array}{c}\text { Cognitive/ } \\
\text { mood }\end{array}$ & Total \\
\hline \multicolumn{6}{|c|}{ Trust support } \\
\hline$r$ value & -0.156 & -0.123 & -0.005 & -0.217 & -0.143 \\
\hline$p$ value & 0.280 & 0.396 & 0.975 & 0.130 & 0.303 \\
\hline \multicolumn{6}{|c|}{ Emotional support } \\
\hline$r$ value & -0.250 & -0.300 & -0.105 & -0.272 & -0.270 \\
\hline$p$ value & 0.080 & 0.034 & 0.469 & 0.056 & 0.058 \\
\hline \multicolumn{6}{|c|}{ Information support } \\
\hline$r$ value & -0.235 & -0.164 & -0.170 & -0.171 & -0.216 \\
\hline$p$ value & 0.100 & 0.256 & 0.237 & 0.236 & 0.132 \\
\hline \multicolumn{6}{|l|}{ Total } \\
\hline$r$ value & -0.265 & -0.241 & -0.117 & -0.271 & -0.259 \\
\hline$p$ value & 0.063 & 0.092 & 0.418 & 0.057 & 0.069 \\
\hline
\end{tabular}

have good relations with their spouses, children, friends and relatives (Table 1).

Findings related to the social support perception scale and PFS average scores of cancer patients are given in Table 2. The average total score of the social support perception scale of cancer individuals is $131.1 \pm 15.5$. The participants' PFS total score average was $5.8 \pm 2.4$ (Table 2).

In Table 3, findings related to the relationship between social support perceptions and fatigue levels of cancer patients are shown. A low level of negative correlation was found between the social support to cancer patients scale emotional support subdimension and the PFS affective subdimension (Table 3).

Findings related to the distribution of average scores of social support perception scale of cancer patients based on various variables are shown in Table 4. There was no statistically significant difference between the social support perception scale and the sociodemographic characteristics of the participants $(p>0.05)$ (Table 4 ).

Findings related to the distribution of the average score of the PFS of the cancer patients based on various variables are shown in Table 5. It is observed that the there is a significant difference between the economic status of the patients and the behaviour/violence subdimension of the PFS $(p<0.05)$. Participants with bad economic status were found to have a lower behaviour/ violence subdimension score than those with better economic status. There was a statistically significant difference between the working status of the participants and the affective subdimension of the PFS $(p<0.05)$. The average score of the affective subdimension of the non-working participants was found to be lower than that of the working ones (Table 5).

Relationship between fatigue and some variables related to sociodemographic and social support in Table 6. Fatigue levels were found to be twice as high in those who had a good relationship with relatives $(t=2.233, p<$ 0.05) (Table 6).

\section{DISCUSSION}

Individuals diagnosed with cancer and their relatives are adversely affected from cognitive, psychological, emotional and social point of view. Especially during this process, the individual has difficulties in coping with many new situations which are related to the disease and needs social support. It is stated in the literature that social support is useful for cancer patients and that there is a positive relationship between emotional support from family members and the level of physical and psychological adjustment to cancer $[13,14]$. A study 
Table 4. Findings related to the distribution of average scores of social support perception scale of cancer patients based on various variables $(n=50)$

\begin{tabular}{|c|c|c|c|c|}
\hline \multirow{2}{*}{ Variable } & \multicolumn{4}{|c|}{ Social support perception scale } \\
\hline & Trust support & Emotional support & Information support & Total \\
\hline \multicolumn{5}{|l|}{ Age, yr } \\
\hline 50 and younger & $56.07 \pm 6.681$ & $41.07 \pm 5.535$ & $29.87 \pm 6.781$ & $127.00 \pm 13.169$ \\
\hline 50 and older & $59.97 \pm 6.569$ & $42.20 \pm 5.805$ & $30.63 \pm 7.511$ & $132.80 \pm 16.264$ \\
\hline$p$ value & 0.61 & 0.524 & 0.737 & 0.229 \\
\hline \multicolumn{5}{|l|}{ Marital status } \\
\hline Married & $58.24 \pm 7.274$ & $41.89 \pm 6.163$ & $30.62 \pm 7.209$ & $130.76 \pm 16.888$ \\
\hline Single & $60.38 \pm 5.026$ & $41.77 \pm 4.285$ & $29.77 \pm 7.585$ & $131.92 \pm 11.161$ \\
\hline$p$ value & 0.332 & 0.948 & 0.719 & 0.818 \\
\hline \multicolumn{5}{|l|}{ Educational status } \\
\hline Illiterate & $59.42 \pm 4.926$ & $42.17 \pm 5.45^{8}$ & $30.50 \pm 9.932$ & $132.08 \pm 18.238$ \\
\hline Literate & $55.71 \pm 11.101$ & $41.29 \pm 9.895$ & $31.00 \pm 6.298$ & $128.00 \pm 25.762$ \\
\hline Primary school & $58.68 \pm 6.638$ & $41.80 \pm 5.074$ & $30.60 \pm 6.627$ & $131.08 \pm 12.560$ \\
\hline High school & $61.67 \pm 3.670$ & $42.17 \pm 3.189$ & $28.67 \pm 5.820$ & $132.50 \pm 7.176$ \\
\hline$p$ value & 0.464 & 0.989 & 0.941 & 0.949 \\
\hline \multicolumn{5}{|l|}{ Economic status } \\
\hline Good & $59.0 \pm 6.042$ & $44.20 \pm 11.234$ & $34.00 \pm 11.683$ & $137.20 \pm 26.985$ \\
\hline Moderate & $58.37 \pm 7.081$ & $41.59 \pm 5.118$ & $30.27 \pm 6.734$ & $130.22 \pm 14.642$ \\
\hline Bad & $63.00 \pm 2.708$ & $41.75 \pm 1.258$ & $27.25 \pm 5.852$ & $132.00 \pm 4.690$ \\
\hline$p$ value & 0.434 & 0.634 & 0.374 & 0.641 \\
\hline \multicolumn{5}{|l|}{ Working status } \\
\hline Working & $55.25 \pm 5.315$ & $42.25 \pm 6.397$ & $30.00 \pm 8.083$ & $127.50 \pm 17.711$ \\
\hline Non-working & $59.11 \pm 6.852$ & $41.83 \pm 5.705$ & $30.43 \pm 7.259$ & $131.37 \pm 15.477$ \\
\hline$p$ value & 0.279 & 0.888 & 0.910 & 0.637 \\
\hline
\end{tabular}

Values are presented as mean $\pm \mathrm{SD}$.

carried out by Ayaz et al. [14] on 200 cancer patients in order to determine the level of social support received by gynecologic cancer shows that patients received support mostly from their families and it is followed respectively by the support provided by a special person and friends. Ozyurt [15] study carried out on 92 patients with the aim of determining the levels of social support given by the cancer patients and the level of perception of this social support by cancer patients shows that patients receives support mostly from their spouses and that it is followed by the support provided by their children and their siblings. Our studies show similarities with the studies of both Ayaz et al. [14] and Ozyurt [15] it is determined that participants receive support mostly from their first-degree relatives (Table 1).

According to a study by Stubblefield et al. [16], fatigue for cancer patients is a symptom increasing over time, having psychological, cognitive and emotional aspects, manifesting itself with diminished energy and increased need for rest, limited concentration and motivation and restriction of daily activities.

In a study by Saygili [12], carried out on 233 cancer patients in order to evaluate the fatigue and quality of life, $76.8 \%$ of participants expressed that they feel fatigued. A study by Karakoc and Yurtsever [17] carried out on 71 patients with the aim of determining the relation between the social support and fatigue in elderly persons receiving chemotherapy, $93 \%$ of the participants stated 
Table 5. Findings related to the distribution of the average score of the Piper Fatigue Scale of the cancer patients based on various variables $(n=50)$

\begin{tabular}{|c|c|c|c|c|c|}
\hline \multirow{2}{*}{ Variable } & \multicolumn{5}{|c|}{ Piper Fatigue Scale } \\
\hline & Behavioral/ severity & Affective meaning & Sensory & Cognitive/mood & Total \\
\hline \multicolumn{6}{|l|}{ Age, yr } \\
\hline 50 and younger & $5.64 \pm 3.182$ & $6.64 \pm 3.205$ & $5.83 \pm 2.768$ & $4.71 \pm 2.601$ & $5.66 \pm 2.628$ \\
\hline 50 and older & $5.99 \pm 3.157$ & $6.36 \pm 2.952$ & $6.58 \pm 2.572$ & $4.80 \pm 2.172$ & $5.88 \pm 2.312$ \\
\hline$p$ value & 0.728 & 0.766 & 0.356 & 0.896 & 0.762 \\
\hline \multicolumn{6}{|l|}{ Marital status } \\
\hline Married & $5.84 \pm 3.068$ & $6.64 \pm 2.887$ & $6.02 \pm 2.593$ & $4.82 \pm 2.456$ & $5.79 \pm 2.469$ \\
\hline Single & $6.00 \pm 3.449$ & $5.89 \pm 3.359$ & $7 \cdot 31 \pm 2.585$ & $4.64 \pm 1.771$ & $5.90 \pm 2.227$ \\
\hline$p$ value & 0.878 & 0.446 & 0.130 & 0.806 & 0.882 \\
\hline \multicolumn{6}{|l|}{ Educational status } \\
\hline Illiterate & $6.50 \pm 2.748$ & $6.58 \pm 3.402$ & $6.83 \pm 2.455$ & $4.58 \pm 2.612$ & $6.07 \pm 2.632$ \\
\hline Literate & $6.93 \pm 2.311$ & $7.34 \pm 1.739$ & $6.77 \pm 2.632$ & $5.79 \pm 1.912$ & $6.68 \pm 1.961$ \\
\hline Primary school & $5.81 \pm 3.330$ & $6.46 \pm 3.157$ & $6.25 \pm 2.683$ & $4.78 \pm 2.165$ & $5.78 \pm 2.362$ \\
\hline High school & $3.72 \pm 3.473$ & $5.03 \pm 2.767$ & $5.37 \pm 3.076$ & $3.97 \pm 2.617$ & $4.46 \pm 2.404$ \\
\hline$p$ value & 0.254 & 0.589 & 0.703 & 0.545 & 0.404 \\
\hline \multicolumn{6}{|l|}{ Economic status } \\
\hline Good & $9.13 \pm 0.639$ & $7.72 \pm 1.874$ & $8.96 \pm 0.865$ & $6.13 \pm 1.697$ & $7.95 \pm 0.873$ \\
\hline Moderate & $5.66 \pm 2.964$ & $6.26 \pm 3.191$ & $6.04 \pm 2.710$ & $4.65 \pm 2.387$ & $5.61 \pm 2.460$ \\
\hline Bad & $4.13 \pm 4.526$ & $6.75 \pm 1.792$ & $6.35 \pm 1.063$ & $4.33 \pm 1.312$ & $5.28 \pm 1.647$ \\
\hline$p$ value & 0.029 & 0.586 & 0.061 & 0.369 & 0.103 \\
\hline \multicolumn{6}{|l|}{ Working status } \\
\hline Working & $7.54 \pm 1.702$ & $9.30 \pm 0.872$ & $7.95 \pm 1.215$ & $5.42 \pm 1.965$ & $7.45 \pm 0.794$ \\
\hline Non-working & $5.74 \pm 3.201$ & $6.20 \pm 2.993$ & $6.22 \pm 2.678$ & $4.72 \pm 2.318$ & $5.67 \pm 2.429$ \\
\hline$p$ value & 0.275 & 0.046 & 0.209 & 0.564 & 0.154 \\
\hline
\end{tabular}

Values are presented as mean $\pm \mathrm{SD}$.

that the most common complaint is fatigue. The lowest score that can be obtained from the Social Support Patient Form is 35 and the highest score is 175. Because of the average social support score was $131.1 \pm 15.5$ in our study, level of the perceived social support of the participants could be evaluated as positive (Table 2).

Cancer is considered to be a family illness because of physical, psychological, and socioeconomic burden to the individual and family. The social support received by individuals facing this difficult situation can encourage them and have an effect on distracting their attention from their disease [18]. Cancer patients sharing their responsibilities with their spouses, children or friends during their illness experience less fatigue [17].
The study by Karakoc and Yurtsever [17] shows a negative relation between fatigue and social support and it also shows that the more the level of fatigue increases, the less social support the patients receive. In our study as well we observed only a sub dimension negative relation between fatigue and social support (Table 3).

Our study, unlike the studies of Gokyildiz Surucu et al. [19] and Karakoc and Yurtsever [17]. show that there is no statistically significant difference between the sociodemographic characteristics and level of social support (Table 4). This situation can be explained by the cultural characteristics of Turkish society. Cultural features such as economic status, gender roles, nutrition, personal hygiene, occupation, family structure, dressing, housing 
Table 6. Relationship between fatigue and some variables related to sociodemographic and social support

\begin{tabular}{|c|c|c|c|c|c|c|}
\hline Characteristic & B & SE & $\beta$ & $t$ & $p$ value & $95 \%$ CI for B \\
\hline \multicolumn{7}{|c|}{ Sociodemographic characteristics } \\
\hline Marital status & -0.167 & 3.246 & -0.008 & -0.052 & 0.959 & -6.719 to 6.384 \\
\hline No. of children & -0.202 & 0.692 & -0.045 & -0.292 & 0.772 & -1.599 to 1.195 \\
\hline Status of education & -1.758 & 1.519 & -0.183 & -1.158 & 0.253 & -4.823 to 1.306 \\
\hline Status of working & -10.177 & 5.672 & -0.292 & -1.794 & 0.080 & -21.623 to 1.270 \\
\hline Economical status & -6.105 & 3.171 & -0.273 & -1.925 & 0.061 & -12.506 to 0.295 \\
\hline Age & 3.268 & 3.689 & 0.158 & 0.886 & 0.381 & -4.177 to 10.713 \\
\hline \multicolumn{7}{|l|}{ Support persons } \\
\hline Partner & 1.747 & $3 \cdot 336$ & 0.081 & 0.524 & 0.603 & -4.989 to 8.483 \\
\hline Children & -1.357 & 3.170 & -0.071 & -0.428 & 0.671 & -7.760 to 5.046 \\
\hline Mother & 8.425 & $7 \cdot 496$ & 0.174 & 1.124 & 0.268 & -6.713 to 23.564 \\
\hline Brothers/sisters & $5 \cdot 385$ & $7 \cdot 419$ & 0.112 & 0.726 & 0.472 & -9.597 to 20.367 \\
\hline Bridge & 3.278 & 4.813 & 0.104 & 0.681 & 0.500 & -6.443 to 12.999 \\
\hline Niece & 1.916 & 10.069 & 0.028 & 0.190 & 0.850 & -18.419 to 22.251 \\
\hline Neighbour & 9.725 & 10.220 & 0.144 & 0.952 & 0.347 & -10.915 to 30.365 \\
\hline \multicolumn{7}{|l|}{ Level of relations } \\
\hline Partner & 0.296 & 1.048 & 0.040 & 0.283 & 0.778 & -1.814 to 2.407 \\
\hline Children & 0.759 & 1.810 & 0.058 & 0.419 & 0.677 & -2.887 to 4.405 \\
\hline Relatives & 22.617 & 10.128 & 0.777 & 2.233 & 0.031 & 2.218 to 43.017 \\
\hline Friends & -15.459 & $9 \cdot 481$ & -0.567 & -1.631 & 0.110 & -34.554 to 3.637 \\
\hline
\end{tabular}

SE, standard error; CI, confidence interval.

regulation, population policy, environmental regulation, and health care practices directly or indirectly influence cancer diagnosis and treatment [20]. Despite the changes and transformations that have occurred with globalization, Turkish society continues to preserve both contemporary and traditional characteristics of the family structure, such as solidarity, cooperation, marital system and the importance of the role of motherhood in women [21]. In the studies by Andrykowski et al. [10] in patients with breast cancer and by Loge et al. [22] in patients with Hodgkin's lymphoma a correlation was found between patients' fatigue and their educational level. The study by Karakoc and Yurtsever [17] shows that the higher the educational level, the less fatigue is observed and perceived social support increases.

Our study shows that, the average score of behaviour/ violence subdimension of $\mathrm{PFS}$ patients with poor economic conditions compared to those with good economic conditions is lower. It is also found out that, non-working patients, compared to working ones, have lowers scores on their affective subdimension of PFS (Table 5). Education increases individuals' ability to establish relationships and may be considered to be one of the factors that affects perceived social support. It is suggested that it is also a factor that ensures that individuals receive concrete assistance from their family, friends and relatives to help them cope with fatigue.

In this study, fatigue levels were found to be twice as high in those who had a good relationship with relatives (Table 6). In Turkish culture, patient visiting by relatives is important. But, sometimes these visits can be too long, and too crowded and can affect the patients negatively. Long period and too crowded visits by relatives may prevent the patient from sleeping during the day. Consequently, patients may not be sufficiently rested $[23,24]$.

Limitations of this study are that it was performed in a single centre and that it was a cross-sectional design. Another limitation of this study is that anemia, and the stage of cancer which are some of the factors that may 
affect fatigue, is not questioned in cancer patients.

As a result of the research, it was seen that the level of fatigue of the participants had moderate and level of perceived social support was positive. Conducting qualitative studies in order to identify the level of fatigue and the level of social support perception of patients would enable individuals to express themselves better, thus facilitating the identification of necessary improvements to that end and contribute to the provision of such support.

\section{KEY MESSAGE}

1. It is determined that participants receive support mostly from their first-degree relatives.

2. It was found that the participants experience moderate fatigue.

3. It was seen that the participants had perceived level of social support was positive.

4. There was no statistically significant difference between the social support perception scale and the sociodemographic characteristics of the participants.

\section{Conflict of interest}

No potential conflict of interest relevant to this article was reported.

\section{Acknowledgments}

We would like to thank all participants in the study. Data from this study has been presented as a poster at the 22th World Congress on Controversies in Obstetrics, Gynaecology \& Infertility (COGI), Budapest (September 17 to 20,2015$)$.

\section{REFERENCES}

1. Stewart BW, Wild CW. World Cancer Report 2014. Lyon (FR): International Agency for Research on Cancer, 2014 [cited 2020 Feb 18]. Available from: https://publications. iarc.fr/Non-Series-Publications/World-Cancer-Reports/ World-Cancer-Report-2014.

2. Cancer Today. Population fact sheets [Internet]. Lyon (FR): International Agency for Research on Cancer, 2020 [cited 2020 Feb 18]. Available from: https://gco.iarc.fr/today/ fact-sheets-populations.

3. Karakoc T. Fatigue and nursing care in cancer patients. Firat Health Serv J 2008;3:99-118.

4. Mock V, Atkinson A, Barsevick A, et al. NCCN practice guidelines for cancer-related fatigue. Oncology (Williston Park) 2000;14:151-161.

5. Bower JE. Cancer-related fatigue: mechanisms, risk factors, and treatments. Nat Rev Clin Oncol 2014;11:597-609.

6. Eylen B. Impact of Informative consultancy on social support skills of the family member of cancer patients [dissertation]. Ankara (TR): Ankara University, Institute of Social Sciences Department of Psychological Services in Education, 2001.

7. Stone P, Richardson A, Ream E, Smith AG, Kerr DJ, Kearney N. Cancer-related fatigue: inevitable, unimportant and untreatable? Results of a multi-centre patient survey. Cancer Fatigue Forum. Ann Oncol 2000;11:971-975.

8. de Jong N, Candel MJ, Schouten HC, Abu-Saad HH, Courtens AM. Prevalence and course of fatigue in breast cancer patients receiving adjuvant chemotherapy. Ann Oncol 2004;15:896-905.

9. Knobel H, Havard Loge J, Lund MB, Forfang K, Nome O, Kaasa S. Late medical complications and fatigue in Hodgkin's disease survivors. J Clin Oncol 2001;19:3226-3233.

10. Andrykowski MA, Curran SL, Lightner R. Off-treatment fatigue in breast cancer survivors: a controlled comparison. J Behav Med 1998;21:1-18.

11. Can G. Assessment of fatigue and care needs of breast cancer patients [dissertation]. Istanbul (TR): Istanbul University, Institute of Medical Sciences, 2001.

12. Saygili U. Assessment of fatigue and quality of life in patients with gastrointestinal system cancer [dissertation]. Gaziantep (TR): University Institute of Medical Sciences, 2012.

13. Alacacioglu A, Ulger E, Varol U, et al. Depression, anxiety and sexual satisfaction in breast cancer patients and their partners: Izmir oncology group study. Asian Pac J Cancer Prev 2014;15:10631-10636.

14. Ayaz S, Yaman ES, Korukluoglu S. Social support level perceived by gynaecological cancer patients and factors affecting it. Turk Clin J Med Sci 2008;28:880-885.

15. Ozyurt BE. A descriptive study on perceived social support level of cancer patients. J Crisis 2007;15:1-15.

16. Stubblefield MD, Custodio CM, Franklin DJ. Cardiopulmonary rehabilitation and cancer rehabilitation. 3 . Cancer rehabilitation. Arch Phys Med Rehabil 2006;87(3 
Suppl 1):S65-S71.

17. Karakoc T, Yurtsever S. Relationship between social support and fatigue in geriatric patients receiving outpatient chemotherapy. Eur J Oncol Nurs 2010;14:61-67.

18. Mitchell T. The social and emotional toll of chemotherapy: patients' perspectives. Eur J Cancer Care (Engl) 2007;16:39-47.

19. Gokyildiz Surucu S, Ozturk, M, Alan S, Usluoglu F, Akbas M, Vurgec Avcibay B. Identification of the level of perceived social support and hope of cancer patients and their Families. World Cancer Res J 2017;4:e886.

20. Yasar Ekici F. Change and transformation of Turkish family structure and assessment of factors affecting this change and transformation. J Acad Soc Sci Stud 2014;30:209-224.
21. Pehlivan S, Yildirim Y, Fadiloglu C. Cancer, culture and nursing. Acibadem Univ J Med Sci 2013;4:168-174.

22. Loge JH, Abrahamsen AF, Ekeberg, Kaasa S. Fatigue and psychiatric morbidity among Hodgkin's disease survivors. J Pain Symptom Manage 2000;19:91-99.

23. Kelebek. Our culture of patient's visit should change [Internet]. Istanbul (TR): Hurriyet Newspaper, 2020 [cited $2020 \mathrm{Feb}$ 18]. Available from: http://www.hurriyet.com.tr/ kelebek/hasta-ziyareti-kulturumuz-degismeli-284956.

24. Guzide K. Thirteen horrible mistakes which we have made in goodwill during patient visits [Internet]. Ankara (TR): Onedio, 2016 [cited $2020 \mathrm{Feb}$ 18]. Available from: https://onedio.com/haber/hasta-ziyaretlerinde-iyi-niyetle-yaptigimiz-13-korkunc-hata-698998. 